\title{
Bi-Level ventilation decreases pulmonary shunt and modulates neuroinflammation in a cardiopulmonary resuscitation model
}

\author{
Robert Ruemmler ${ }^{\text {Corresp., } 1}{ }^{1}$, Alexander Ziebart ${ }^{1}$, Frances Kuropka ${ }^{1}$, Bastian Duenges ${ }^{1}$, Jens Kamuf ${ }^{1}$, Andreas Garcia- \\ Bardon $^{1}$, Erik K Hartmann ${ }^{1}$ \\ ${ }^{1}$ Department of Anesthesiology, Medical Centre of the Johannes Gutenberg-University, Mainz, Germany \\ Corresponding Author: Robert Ruemmler \\ Email address: robert.ruemmler@email.de
}

Background: Optimal ventilation strategies during cardiopulmonary resuscitation are still heavily debated and poorly understood. So far, no convincing evidence could be presented in favour of outcome relevance and necessity of specific ventilation patterns. In recent years, alternative models to the guideline-based intermittent positive pressure ventilation (IPPV) have been proposed. In this randomized controlled trial, we evaluated a bi-level ventilation approach in a porcine model to assess possible physiological advantages for the pulmonary system as well as resulting changes in neuroinflammation compared to standard measures.

Methods: 16 male German landrace pigs were anesthetized and instrumented with arterial and venous catheters. Ventricular fibrillation was induced and the animals were left untreated and without ventilation for 4 minutes. After randomization, the animals were assigned to either the guideline-based group (IPPV, tidal volume $8-10 \mathrm{ml} / \mathrm{kg}$, respiratory rate $10 / \mathrm{min}, \mathrm{F}_{\mathrm{i}} \mathrm{O}_{2} 1.0$ ) or the bi-level group (inspiratory pressure levels $15-17 \mathrm{cmH}_{2} \mathrm{O} / 5 \mathrm{cmH}_{2} \mathrm{O}$, respiratory rate $10 / \mathrm{min}, \mathrm{F}_{\mathrm{i}} \mathrm{O}_{2} 1.0$ ). Mechanical chest compressions and interventional ventilation were initiated and after 5 minutes, blood samples, including ventilation/perfusion measurements via multiple inert gas elimination technique, were taken. After 8 minutes, advanced life support including adrenaline administration and defibrillations were started for up to 4 cycles. Animals achieving ROSC were monitored for 6 hours and lungs and brain tissue were harvested for further analyses.

Results: 5 of the IPPV and 4 of the bi-level animals achieved ROSC. While there were no significant differences in gas exchange or hemodynamic values, bi-level treated animals showed less pulmonary shunt directly after ROSC and a tendency to lower inspiratory pressures during CPR. Additionally, cytokine expression of Tumour-necrosis factor alpha was significantly reduced in hippocampal tissue compared to IPPV animals.

Conclusion: Bi-level ventilation with a constant positive end expiratory pressure and pressure-controlled ventilation is not inferior in terms of oxygenation and decarboxylation when compared to guideline-based IPPV ventilation. Additionally, bi-level ventilation showed signs for a potentially ameliorated neurological outcome as well as less pulmonary shunt following experimental resuscitation. Given the restrictions of the animal model, these advantages should be further examined. 
2

3 Bi-Level ventilation decreases pulmonary shunt and modulates 4 neuroinflammation in a cardiopulmonary resuscitation model

5 Robert Ruemmler ${ }^{1}$, Alexander Ziebart ${ }^{1}$, Frances Kuropka ${ }^{1}$, Bastian Duenges ${ }^{1}$, Jens

6 Kamuf $^{1}$, Andreas Garcia-Bardon ${ }^{1}$, Erik Kristoffer Hartmann ${ }^{1}$

7

${ }^{1}$ Department of Anesthesiology, Medical Centre of the Johannes Gutenberg-University

Corresponding author:

Robert Ruemmler

Langenbeckstrasse 1

55131 Mainz, Germany

+491631-179817

Robert.ruemmler@unimedizin-mainz.de

Word count: 2540

Abstract: 331 words 


\section{Abstract}

Background: Optimal ventilation strategies during cardiopulmonary resuscitation are still heavily debated and poorly understood. So far, no convincing evidence could be presented in favour of outcome relevance and necessity of specific ventilation patterns. In recent years, alternative models to the guideline-based intermittent positive pressure ventilation (IPPV) have been proposed. In this randomized controlled trial, we evaluated a bi-level ventilation approach in a porcine model to assess possible physiological advantages for the pulmonary system as well as resulting changes in neuroinflammation compared to standard measures.

Methods: 16 male German landrace pigs were anesthetized and instrumented with arterial and venous catheters. Ventricular fibrillation was induced and the animals were left untreated and without ventilation for 4 minutes. After randomization, the animals were assigned to either the guideline-based group (IPPV, tidal volume $8-10 \mathrm{ml} / \mathrm{kg}$, respiratory rate $10 / \mathrm{min}, \mathrm{F}_{\mathrm{i}} \mathrm{O}_{2} 1.0$ ) or the bilevel group (inspiratory pressure levels $15-17 \mathrm{cmH}_{2} \mathrm{O} / 5 \mathrm{cmH}_{2} \mathrm{O}$, respiratory rate $10 / \mathrm{min}, \mathrm{F}_{\mathrm{i}} \mathrm{O}_{2}$ 1.0). Mechanical chest compressions and interventional ventilation were initiated and after 5 minutes, blood samples, including ventilation/perfusion measurements via multiple inert gas elimination technique, were taken. After 8 minutes, advanced life support including adrenaline administration and defibrillations were started for up to 4 cycles. Animals achieving ROSC were monitored for 6 hours and lungs and brain tissue were harvested for further analyses.

Results: 5 of the IPPV and 4 of the bi-level animals achieved ROSC. While there were no significant differences in gas exchange or hemodynamic values, bi-level treated animals showed less pulmonary shunt directly after ROSC and a tendency to lower inspiratory pressures during CPR. Additionally, cytokine expression of Tumour-necrosis factor alpha was significantly reduced in hippocampal tissue compared to IPPV animals.

Conclusion: Bi-level ventilation with a constant positive end expiratory pressure and pressurecontrolled ventilation is not inferior in terms of oxygenation and decarboxylation when compared to guideline-based IPPV ventilation. Additionally, bi-level ventilation showed signs for a potentially ameliorated neurological outcome as well as less pulmonary shunt following 
80 experimental resuscitation. Given the restrictions of the animal model, these advantages should 81 be further examined.

82

83

84

85 Keywords: Resuscitation, Ventilation, Neuroinflammation, MIGET, Lung Protection, bi-level,

86 Pig, porcine

87

88

89

90

91

92

93

94

95

96

97

98

99

100

101

102

103

104

105

106

107

108

109

110

111

Peer] reviewing PDF | (2019:12:43729:2:0:NEW 29 Mar 2020) 


\section{Introduction}

Cardiac arrest and cardiopulmonary resuscitation (CPR) are regularly encountered scenarios in clinical, as well as pre-hospital situations. With incidence rates of up to $0.1 \%$ per year and an overall mortality rate close to $90 \%$, there is still a lack of effective and evidence-based treatment options to prevent permanent damage or death (1). While there have been changes to resuscitation guidelines in Europe and the U.S. regarding early defibrillation and high-quality chest compressions, guideline-based ventilation recommendations have not been substantially changed in almost two decades ${ }^{(2-5)}$. In recent years, several alternatives to the standard intermittent positive pressure ventilation (IPPV) method with a fixed respiratory rate (RR) of 10 breaths per minute have been proposed. Ranging from synchronized ventilation in order to suppress chest compression interference ${ }^{(6)}$ to ultra-low-tidal-volume ventilation to mitigate possible lung injuries $^{(7)}$ up to mere passive oxygenation via high-flow oxygenation supply ${ }^{(8,9)}$, many approaches have been tested and have shown - in parts - promising results. However, due to the complexity of the topic and obvious ethical problems while designing and conducting prospective randomized-treatment resuscitation study protocols, convincing evidence to change current recommendations is still missing ${ }^{(10)}$. In this study, we wanted to further evaluate a previously proposed approach of a pressure-controlled bi-level ventilation model during cardiopulmonary resuscitation in swine $^{(11)}$. Based on our own research ${ }^{(7)}$, our main hypothesis was that this ventilation mode could result in lower tidal volumes and peak inspiratory pressures and might improve oxygenation parameters during and especially after return of spontaneous circulation (ROSC). Secondly, we assumed that these effects could provide favourable remote end organ effects and reduce hypoxic neuroinflammation after successful resuscitation.

\section{Methods}


Anaesthesia/Instrumentation

145

Following approval of the study by the State and Institutional Animal Care Committee Rhineland Palatine (Landesuntersuchungsamt Rheinland-Pfalz, approval no. G16-1042), 16 male German landrace pigs (12-16 weeks, 30-35 kg) were acquired from a local farm and received pre-transport sedation via an intramuscular injection of azaperone and ketamine $(4 \mathrm{mg} / \mathrm{kg})$. Instrumentation and animal preparation as well as extended cardiovascular monitoring were carried out as described before by our group $^{(7)}$. Specifically, constant anesthesia was maintained during the entire experiment using propofol and fentanyl infusions, a base ventilation was established (6-8 ml/kgBW, PEEP $5 \mathrm{cmH}_{2} \mathrm{O}$, peak inspiratory pressure of $40 \mathrm{cmH}_{2} \mathrm{O}$, adapted respiratory rate to adequate $\mathrm{CO}_{2}$ levels) and central venous and arterial access was established under ultra sound guidance ${ }^{(7)}$. A transpulmonary thermodilution catheter (PiCCO, Pulsion, Munich, Germany), a Swan-Ganz-catheter and an intravenous pacing catheter (Osypka Medical GmbH, Rheinfelden-Herten, Germany) were placed as established previously(7). The fasting animals received an initial fluid bolus of $30 \mathrm{ml} / \mathrm{kg}$ balanced electrolyte solution and were left to stabilize for 30 minutes before baseline measurements were taken. Mean arterial blood pressure was maintained above a threshold of $50 \mathrm{mmHg}$ using norepinephrine infusion, if necessary.

Intervention:

Following base line measurements, ventricular fibrillation was induced via the fibrillation catheter (13.8 V current at $200 \mathrm{~Hz}$ according to manufacturer's recommendation) and the ventilator was disconnected(7). Monitor-confirmed cardiac arrest was permitted for four minutes and the animals were randomized into two groups by blinded drawing of 1 of 16 envelopes containing the respective ventilation mode ( 8 animals per group): 
173 Group 1 (“IPPV”, standard) )received guideline-based intermittent positive pressure

174 ventilation (IPPV), $\mathrm{V}_{\mathrm{t}}:$ 8-10ml/kg, RR: 10/min, $\mathrm{F}_{\mathrm{i}} \mathrm{O}_{2}: 1.0$

175

176

Group 2 ("bi-level") received bi-level ventilation with pressure levels of $15-17 \mathrm{cmH}_{2} \mathrm{O}$

177 maximum inspiratory pressure and $5 \mathrm{cmH}_{2} \mathrm{O}$ minimum pressure, $\mathrm{RR}$ : 10/min, $\mathrm{F}_{\mathrm{i}} \mathrm{O}_{2}$ : 1.0. Peak inspiratory pressure levels were determined by assessing the average pressure necessary to result in a pre-CPR tidal volume of $6-8 \mathrm{ml} / \mathrm{kgBW}$.

Standardized mechanical chest compressions using a LUCAS-2 device (PhysioControl, Lund, Sweden) with a fixed compression rate of 100/min and the randomized ventilation mode were then initiated following an established protocol(7). After five minutes of continuous CPR, blood samples were collected and resuscitation measures were continued according to the advanced life support algorithm: two minute compression cycles, rhythm analysis, defibrillation (200J, bi-phasic, electrodes in anterior-posterior position), epinephrine $(1 \mathrm{mg})$ and vasopressine $(0.1 \mathrm{U} / \mathrm{kg})$ administration. If ROSC was not achieved after the 4th defibrillation, the experiment was terminated. Animals achieving ROSC were switched back to standard ventilation and monitored for six hours. During the monitoring period, mean arterial blood pressure was kept over $50 \mathrm{mmHg}$ using a norepinephrine drip if necessary. The experiment was terminated with the animal being euthanized in deep anesthesia using high doses of propofol (200mg) and potassium chloride $(40 \mathrm{mmol})$.

\section{Measurements/sample collection:}

Cardiopulmonary and respiratory values were constantly measured and collected for the duration of the whole experiment as described before ${ }^{(7)}$ including spirometry, ventilation pressures and hemodynamics. Additionally, blood gas analyses and cardiac output (CO) measurements were taken at baseline, during CPR, ten minutes post-CPR and hourly afterwards. 
203 Ventilation/perfusion (V/Q) analyses were performed at baseline, during CPR and ten 204 minutes post-CPR using the micropore membrane inlet mass spectrometry facilitated 205 multiple inert gas elimination technique (MMIMS-MIGET, Oscillogy LLC, Philadelphia,

206

207

208

209

210

211

212

213

214

215

216

217

218

219

220

221

222

223

224

225

226

227

228

229

230

231

232

233 USA) as described before ${ }^{(12)}$. Specifically, subclinical, non-toxic doses of a saline solution containing six chemically inert gases with different elimination constants (sulphur hexafluoride, krypton, desflurane, enflurane, diethyl ether and acetone) were infused starting 20 minutes prior to measurements in order to reach an in vivo steady state. Blood samples from the pulmonary and femoral artery were taken and analyzed via a mass spectrometer determining gas elimination during lung passage, thus allowing accurate $V / Q$ fraction determination for high, normal and low perfusion ratios as well as shunt volumes.

After termination, both lungs were harvested and samples from upper and lower left lung lobe were either snap frozen for biomolecular analyses or preserved in $2 \%$ formaldehyde solution for histologic fixation. The right upper lobe was used for wet-todry ratio measurements. A previously established tissue damage score was used in investigator-blinded manner to quantify histologic injury as described before $(13,14)$. RNA extraction and real-time polymerase chain reaction measurements were performed in lung tissue, cortex and hippocampus samples using a relative RNA quantification kit with a cyclophilin A (peptidylprolyl isomerase A, PPIA) reference and a Lightcycler 480 system (LightCycler, Roche, Mannheim, Germany) according to manufacturer's instructions in order to determine cytokine expression levels of proinflammatory interleukin 6 (IL-6) and tumor necrosis factor alpha (TNFa) $)^{(7)}$.

Statistical analyses were performed using 2-way ANOVA inter-group tests with post-hoc Bonferroni correction for repeated measurements (e.g. blood pressures, inspiratory pressures) as well as Mann-Whitney $U$ test for single measurements (e.g. IL-6, TNFalpha, MIGET) with Student-Newman-Keuls post-hoc analysis via GraphPad Prism 8 software (GraphPad Software Inc., La Jolla, CA, USA). All data in the text are presented as mean (standard deviation). Bar plots are shown as mean with the standard error of the mean- P-values $<0.05$ were considered significant.

\section{Results}


235 A total of 16 experiments were performed. ROSC was achieved in 5 of the IPPV and 4 236 of the bi-level animals (62.5\% versus $50 \%)$. No substantial fractures, macroscopic

237 injuries or pneumothoraces were detected in any of the animals after mechanical chest 238 compressions. There were no significant differences in haemodynamic values between 239 the two groups at any given time point (Table 1). There were neither inter-group

240

241

242

243

244

245

246

247

248

249

250

251

252

253

254

255

256

257

258

259

260

261

262

263

264 differences in vasopressor need during and after successful CPR nor in the number of defibrillations to achieve ROSC. Horovitz's index $\left(\mathrm{PaO}_{2} / \mathrm{FiO}_{2}\right)$ in surviving animals showed no difference over the whole monitoring period as well as during CPR (Fig. 1). $\mathrm{PaCO}_{2}$ values were not higher under bi-level ventilation during CPR and showed no difference after ROSC. Peak inspiratory pressures were significantly decreased during ROSC in the bilevel group ( $P=0.005)$ but showed no difference in delivered tidal volumes.(Fig.2) Post ROSC, necessary inspiratory pressures tended to be decreased, but did not show statistical significance.

Ventilation/perfusion analyses showed no major differences in all lung areas (high $V / Q$, medium V/Q and low $V / Q$ ) during CPR but significantly less pulmonary shunt immediately post-ROSC in the bi-level group (IPPV: 26.8 (16.2) [\% of cardiac output]; bi-level: 9.4 (8.2) [\% of cardiac output], $\mathrm{P}=0.017)$ (Fig.3).

Lung histology showed no significant differences in tissue damage scores. The pulmonary wet-to-dry ratio did not differ between both groups. IL-6 and TNFa mRNA expression showed no difference in lung and cortical tissue but was decreased in hippocampal samples of the animals receiving bi-level ventilation with a statistically

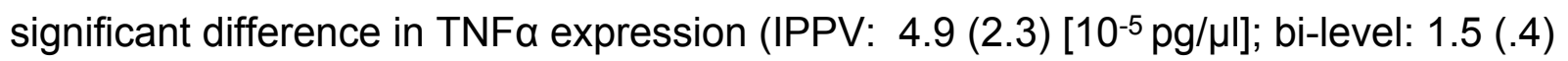
$\left.\left[10^{-5} \mathrm{pg} / \mu \mathrm{l}\right], P=0.032\right)$ (Fig. 4).

\section{Discussion}

The present study compared standard IPPV ventilation to a novel bi-level ventilation regimen with a previously described comparable gas exchange ${ }^{(11)}$ in a resuscitation scenario in a prospective randomized animal trial. While we could not show any 
265 significant differences in haemodynamic values or oxygenation patterns at any point 266 during the trial, there were some results suggesting beneficial effects on overall gas 267 exchange, lung physiology and organ perfusion.

Although there were moderate decreases in tidal volume and significantly decreased inspiratory pressures during bi-level ventilation, no significant oxygenation changes, decarboxylation impairments or decreased histological and inflammatory changes in lung tissue could be detected. Previous studies suggested mitigated pulmonary tissue damage when low-volume ventilation was applied during $\mathrm{CPR}^{(7)}$, but compared to the applied volumes in our study $\left(\mathrm{V}_{\mathrm{t}}\right.$ resulting in values around 6-8 $\left.\mathrm{ml} / \mathrm{kg}\right)$, those tidal volumes were substantially lower $\left(\mathrm{V}_{\mathrm{t}} 2-3 \mathrm{ml} / \mathrm{kg}\right)$. However, we could detect a similar decrease in neuroinflammation, especially in hippocampal tissue $6 \mathrm{~h}$ after achieving ROSC. While those effects were small and only 4 animals survived, they were statistically significant and might point towards a better cerebral perfusion during lower volume ventilation under CPR, which is consistent with prospectively generated data from our group ${ }^{(7)}$ as well as retrospective clinical analyses of out-of-hospital cardiac arrest showing favourable neurological outcome when ventilated with lower tidal volumes $^{(15)}$.

MMIMS-MIGET measurements showed significantly less shunt volumes in bi-level ventilated animals compared to IPPV. While MIGET measurements depend on reliable cardiac output measurements and a steady state of infused inert gases, our group could repeatedly show that viable values can be obtained under extreme circumstances like CPR $(7,12)$. Compared to those studies, no dramatically increased high V/Q fractions indicating hyperventilation and additional shear stress could be detected. This is expected, since differences in inspiratory pressure and respiratory rates are not as pronounced as they were in these trials. The application of a constant end-expiratory pressure during ventilation might improve recruitment of compressed lung areas, thus increasing ventilated areas and allowing for lower inspiratory pressures without compromising adequate gas exchange. Additionally, lower inspiratory and consequently 
295 intrathoracic pressures might result in improved venous return and better lung

296 perfusion, although this remains controversial(16).

297 These effects combined could explain the objective differences and might even be

298 responsible for a better pulmonary outcome when applied over prolonged periods of

299 CPR. Another explanation for an improved lung perfusion could be the use of vasopressine, which has been shown before to increase organ perfusion during resuscitation (17) and, in our own experience, can help to increase ROSC rates.

This study has several limitations. While the presented ROSC rates match with those of other resuscitation trials, no statement can be made about increased or decreased overall mortality regarding one ventilation method over the other due to restricted sample sizes, several confounding factors when working with large animals and the pilot character of the study potentially affecting $\operatorname{CPR}^{(18,19)}$. For example, in a comparable resuscitation model, Kill et al. showed successful resuscitation rates ranging from 40$80 \%$ over several studies and with different ventilation strategies ${ }^{(6,11)}$. Additionally, the no-flow time in this trial is significantly shorter compared to other resuscitation experiments and might not yield realistic results when applied to out of hospital cardiac arrest scenarios $^{(20)}$. Tan et al. showed a decline in ROSC rates when animals were subjected to 8 minutes of no-flow time compared to 4 minutes as presented in our study(21), underlining the need for further examination of the presented results. The use of bi-level ventilation itself can be seen as controversial, since this is primarily described as a non-invasive ventilation mode, often used to support infants or patients suffering from respiratory failure ${ }^{(22)}$. Additionally, this mode has been shown to produce increased inspiratory pressures, when applied during $\mathrm{CPR}^{(23)}$. Although we could not observe these pressure peaks in our study and have no indication of resulting pulmonary damage, a specific pressure profile analysis might be warranted in future studies. Alternatively, the added thoracic and inspiratory pressures during CPR as well as potentially unreliable tidal volume delivery of standard ventilation modes could be counteracted with more modern, synchronized ventilation strategies like chest compression synchronized ventilation (CCSV). This has been shown to provide adequate ventilation and oxygenation ${ }^{(11)}$ while potentially causing increased lung stress 
326 due to higher inspiratory pressures. The use of PEEP during CPR is not recommended

327 in any resuscitation guideline to date for the lack of data and the fear of compromised

328 circulation and cardiac filling during chest compressions. However, we could not detect

329 any disadvantages or pressure differences during this study and showed in a previous

330 trial, that moderate PEEP had no negative effects ${ }^{(7)}$. However, in this study, we chose to

331 adhere to the resuscitation guidelines of the ERC, which up to this point do not

332 recommend PEEP in their ventilation protocol during CPR. The omission of PEEP in the

333 control group might itself be responsible for some of the effects, but since no sufficient

334 data on this topic is available right now, separate experiments are planned by our group

335 to explore possible benefits of different PEEP levels alone.

336 The direct measurement of intrathoracic pressures as a sophisticated and technically

337 challenging method has not been considered in this study but would help to further

338 evaluate ventilation effects and confirm potentially beneficial mechanisms and their

339 causation. The use of MIGET measurements during CPR is sophisticated. Although

340 several experiments of our group yielded comparable and reasonable results, validation

341 of another experimental group in a large animal model is still missing ${ }^{(7,12)}$. Since

342 measurements of $V / Q$ depend on adequate cardiac output measurements and a steady

343 state of the infused gases to eliminate, the face validity of gained results might be

344 debatable. Apart from IL-6 and TNFalpha measurements, no cerebral parameters were

345 taken. While it would- in theory- be feasible to measure intracranial pressure during and

346 after CPR, we decided against inflicting additional pre-CPR trauma to the head to

347 prevent more confounding factors from influencing inflammatory responses.

Conclusion

350

351 In a porcine CPR model, bilevel ventilation was not inferior to standard IPPV and

352 allowed for adequate gas exchange despite decreased inspiratory pressures and

353 slightly reduced tidal volumes. In early ROSC, less pulmonary shunt could be detected,

354 suggesting improved pulmonary ventilation/perfusion status in bilevel animals.

355 Decreased neuroinflammatory cytokine markers point towards a better end organ

356 perfusion under bi-level ventilation, possibly affecting neurologic outcomes. Given the 
357 short no-flow time and the character of this study, further examinations are necessary to

358 better characterize this alternative ventilation technique and its value during

359

360

361

362

363

364

365

366

367

368

369

370

371

372

373

374

375

376

377

378

379

380

381

382

383

384

385

386

387

388

389

390

391

392

393

394

resuscitation.

\section{Declarations/Acknowledgements}

Competing interests: The authors declare that they have no competing interests.

Funding: The authors received no funding for this work.

Consent for publication: Not applicable.

Acknowledgements: The authors want to thank Dagmar Dirvonskis and Dana Pieter for excellent technical support. Parts of this study are included in the doctoral thesis of FK.

\section{Legend}

Figure $1 \mathrm{Gas}$ exchange $\left(\mathbf{A}\right.$ : arterial partial pressure of carbon dioxide $\left(\mathrm{PaCO}_{2}\right)$; $\mathbf{B}$ : Horovitz's ratio $\left.\left(\mathrm{PaO}_{2} / \mathrm{F}_{i} \mathrm{O}_{2},\right)\right)$ measured via blood gas analyses over different time points (baseline healthy (BLH), CPR, ROSC and 1 hour after ROSC). There were no significant differences in oxygenation or decarboxylation values during CPR and after achieving ROSC. The initial gas exchange impairment is typical and fully recovers after $1-2 \mathrm{~h}$ post ROSC. No major differences developed over the monitoring period afterwards.

Figure 2: Ventilation parameters. Depicted are peak inspiratory pressures $(\mathbf{A})$, mean airway pressures $(\mathbf{B})$ and mean tidal volumes $(\mathbf{C})$ over different time points (baseline healthy (BLH), CPR, ROSC and 1 hour after ROSC). Peak inspiratory pressures were significantly lower in bilevel animals $(P=0.005)$ during ROSC with no statistically significant difference in tidal volumes $(P=0.16)$ or mean airway pressures $(P=0.11)$. Post-ROSC, bilevel animals tended to lower inspiratory pressures without statistical significance. No changes were detected after the $1 \mathrm{~h}$ time point.

Figure 3: MIGET measurements of pulmonary shunt-(A), low- (B), medium- (C) and high (D) ventilation/perfusion ratio volumes over different time points (baseline healthy (BLH), CPR, ROSC, 3 hours and 6 hours after ROSC). Directly after achieving ROSC, 
395

the animals showed significantly less shunt after bi-level ventilation $(P=0.017)$. There were no differences in low, middle or high ventilation/perfusion areas.

Figure 4: Inflammatory marker expressions of interleukin-6 (IL-6, A,B) and tumour necrosis factor alpha (TNF alpha, C,D) in cortical and hippocampal tissue relative to PPIA expression. While there were no statistical differences in cortical samples, hippocampal tissue showed decreased expression levels of TNFalpha and IL-6. Statistical analyses only proved to be significant for TNFalpha $(P=0.032)$.

1. Grasner JT, Lefering R, Koster RW, Masterson S, Bottiger BW, Herlitz J, Wnent J, Tjelmeland IB, Ortiz FR, Maurer $H$, Baubin M, Mols P, Hadzibegovic I, loannides $M$, Skulec R, Wissenberg $M$, Salo A, Hubert H, Nikolaou NI, Loczi G, Svavarsdottir H, Semeraro F, Wright PJ, Clarens C, Pijls R, Cebula G, Correia VG, Cimpoesu D, Raffay V, Trenkler S, Markota A, Stromsoe A, Burkart R, Perkins GD, Bossaert LL. EuReCa ONE-27 Nations, ONE Europe, ONE Registry: A prospective one month analysis of out-of-hospital cardiac arrest outcomes in 27 countries in Europe. Resuscitation. 2016;105:188-95.

2. Brooks SC, Anderson ML, Bruder E, Daya MR, Gaffney A, Otto CW, Singer AJ, Thiagarajan RR, Travers AH. Part 6: Alternative Techniques and Ancillary Devices for Cardiopulmonary Resuscitation: 2015 American Heart Association Guidelines Update for Cardiopulmonary Resuscitation and Emergency Cardiovascular Care. Circulation. 2015;132(18 Suppl 2):S436-43.

3. Callaway CW, Soar J, Aibiki M, Bottiger BW, Brooks SC, Deakin CD, Donnino MW, Drajer S, Kloeck W, Morley PT, Morrison L, Neumar RW, Nicholson TC, Nolan JP, Okada K, O'Neil BJ, Paiva EF, Parr MJ, Wang TL, Witt J. Part 4: Advanced Life Support: 2015 International Consensus on Cardiopulmonary Resuscitation and Emergency Cardiovascular Care Science With Treatment Recommendations. Circulation. 2015;132(16 Suppl 1):S84-145.

4. Sandroni C, Nolan J. ERC 2010 guidelines for adult and pediatric resuscitation: summary of major changes. Minerva anestesiologica. 2011;77(2):220-6.

5. Tanaka H, Ong MEH, Siddiqui FJ, Ma MHM, Kaneko H, Lee KW, Kajino K, Lin CH, Gan HN, Khruekarnchana P, Alsakaf O, Rahman NH, Doctor NE, Assam P, Shin SD. Modifiable Factors Associated With Survival After Out-of-Hospital Cardiac Arrest in the Pan-Asian Resuscitation Outcomes Study. Annals of emergency medicine. 2017.

6. Kill C, Galbas M, Neuhaus C, Hahn O, Wallot P, Kesper K, Wulf H, Dersch W. Chest Compression Synchronized Ventilation versus Intermitted Positive Pressure Ventilation during Cardiopulmonary Resuscitation in a Pig Model. PloS one. 2015;10(5):e0127759. 
441 7. Ruemmler R, Ziebart A, Moellmann C, Garcia-Bardon A, Kamuf J, Kuropka F, Duenges B, 442 Hartmann EK. Ultra-low tidal volume ventilation-A novel and effective ventilation strategy during 443 experimental cardiopulmonary resuscitation. Resuscitation. 2018;132:56-62.

4448 8. Deakin CD, O'Neill JF, Tabor T. Does compression-only cardiopulmonary resuscitation generate 445 adequate passive ventilation during cardiac arrest? Resuscitation. 2007;75(1):53-9.

4469 9. Koster RW, Deakin CD, Bottiger BW, Zideman DA. Chest-compression-only or full 447 cardiopulmonary resuscitation? Lancet (London, England). 2007;369(9577):1924; author reply 5.

448 10. Rubulotta F, Rubulotta G. Cardiopulmonary resuscitation and ethics. Revista Brasileira de 449 Terapia Intensiva. 2013;25(4):265-9.

450 11. Kill C, Hahn O, Dietz F, Neuhaus C, Schwarz S, Mahling R, Wallot P, Jerrentrup A, Steinfeldt T, 451 Wulf $\mathrm{H}$, Dersch $\mathrm{W}$. Mechanical ventilation during cardiopulmonary resuscitation with intermittent 452 positive-pressure ventilation, bilevel ventilation, or chest compression synchronized ventilation in a pig 453 model. Critical care medicine. 2014;42(2):e89-95.

454 12. Hartmann EK, Duenges B, Boehme S, Szczyrba M, Liu T, Klein KU, Baumgardner JE, Markstaller K, 455 David $M$. Ventilation/perfusion ratios measured by multiple inert gas elimination during experimental 456 cardiopulmonary resuscitation. Acta anaesthesiologica Scandinavica. 2014;58(8):1032-9.

457 13. Ziebart A, Garcia-Bardon A, Kamuf J, Thomas R, Liu T, Schad A, Duenges B, David M, Hartmann 458 EK. Pulmonary effects of expiratory-assisted small-lumen ventilation during upper airway obstruction in 459 pigs. Anaesthesia. 2015;70(10):1171-9.

460 14. Ziebart A, Hartmann EK, Thomas R, Liu T, Duenges B, Schad A, Bodenstein M, Thal SC, David M. 461 Low tidal volume pressure support versus controlled ventilation in early experimental sepsis in pigs.

462 Respiratory research. 2014;15:101.

463 15. Beitler JR, Ghafouri TB, Jinadasa SP, Mueller A, Hsu L, Anderson RJ, Joshua J, Tyagi S, Malhotra A, 464 Sell RE, Talmor D. Favorable Neurocognitive Outcome with Low Tidal Volume Ventilation after Cardiac 465 Arrest. Am J Respir Crit Care Med. 2017;195(9):1198-206.

466 16. Georgiou M, Papathanassoglou E, Xanthos T. Systematic review of the mechanisms driving 467 effective blood flow during adult CPR. Resuscitation. 2014;85(11):1586-93.

468 17. Meybohm P, Cavus E, Dorges V, Steinfath M, Sibbert L, Wenzel V, Scholz J, Bein B. Revised 469 resuscitation guidelines: adrenaline versus adrenaline/vasopressin in a pig model of cardiopulmonary 470 resuscitation--a randomised, controlled trial. Resuscitation. 2007;75(2):380-8.

471 18. Holda MK, Holda J, Koziej M, Piatek K, Klimek-Piotrowska W. Porcine heart interatrial septum 472 anatomy. Ann Anat. 2018;217:24-8.

473 19. Hsu FS, Du SJ. congenital heart diseases in swine. Vet Pathol. 1982;19(6):676-86.

$47420 . \quad K j a e r g a a r d ~ B$, Bavarskis E, Magnusdottir SO, Runge C, Erentaite D, Vogt JS, Bendtsen MD. Four 475 ways to ventilate during cardiopulmonary resuscitation in a porcine model: a randomized study.

476 Scandinavian journal of trauma, resuscitation and emergency medicine. 2016;24:67.

477 21. Tan D, Sun J, Geng P, Ling B, Xu J, Walline J, Yu X. Duration of cardiac arrest requires different 478 ventilation volumes during cardiopulmonary resuscitation in a pig model. J Clin Monit Comput. 2019.

479 22. Gillis-Haegerstrand C, Markstrom A, Barle H. Bi-level positive airway pressure ventilation 480 maintains adequate ventilation in post-polio patients with respiratory failure. Acta anaesthesiologica 481 Scandinavica. 2006;50(5):580-5.

482 23. Speer T, Dersch W, Kleine B, Neuhaus C, Kill C. Mechanical Ventilation During Resuscitation: How 483 Manual Chest Compressions Affect a Ventilator's Function. Adv Ther. 2017;34(10):2333-44. 


\section{Figure 1}

Gas exchange and oxygenation values

Gas exchange (A: arterial partial pressure of carbon dioxide $\left(\mathrm{PaCO}_{2}\right)$; B: Horovitz's ratio $\left.\left(\mathrm{PaO}_{2} / \mathrm{F}_{i} \mathrm{O}_{2},\right)\right)$ measured via blood gas analyses over different time points (baseline healthy (BLH), CPR, ROSC and 1 hour after ROSC). There were no significant differences in oxygenation or decarboxylation values during CPR and after achieving ROSC. The initial gas exchange impairment is typical and fully recovers after $1-2 \mathrm{~h}$ post ROSC. No major differences developed over the monitoring period afterwards. 


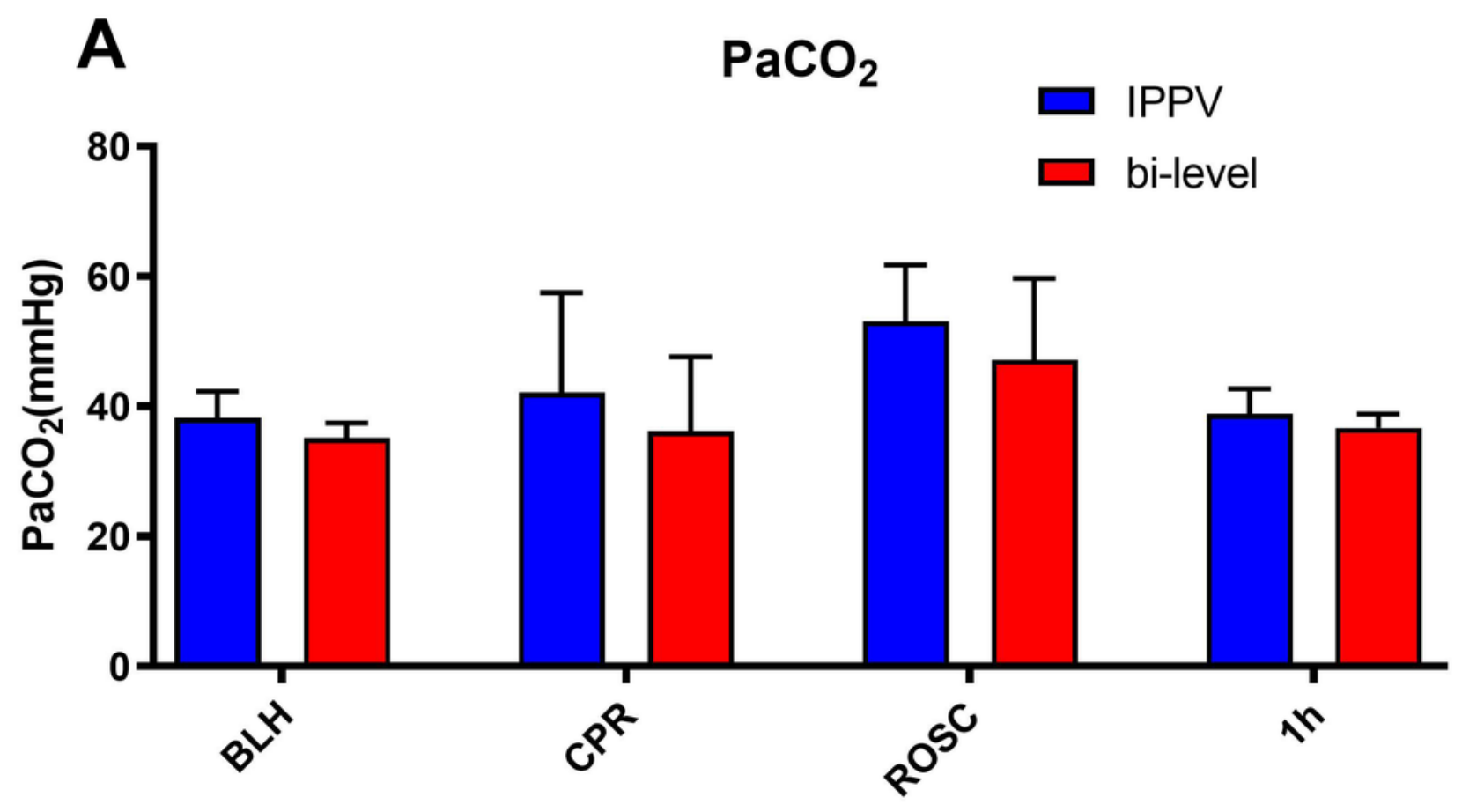

Time point

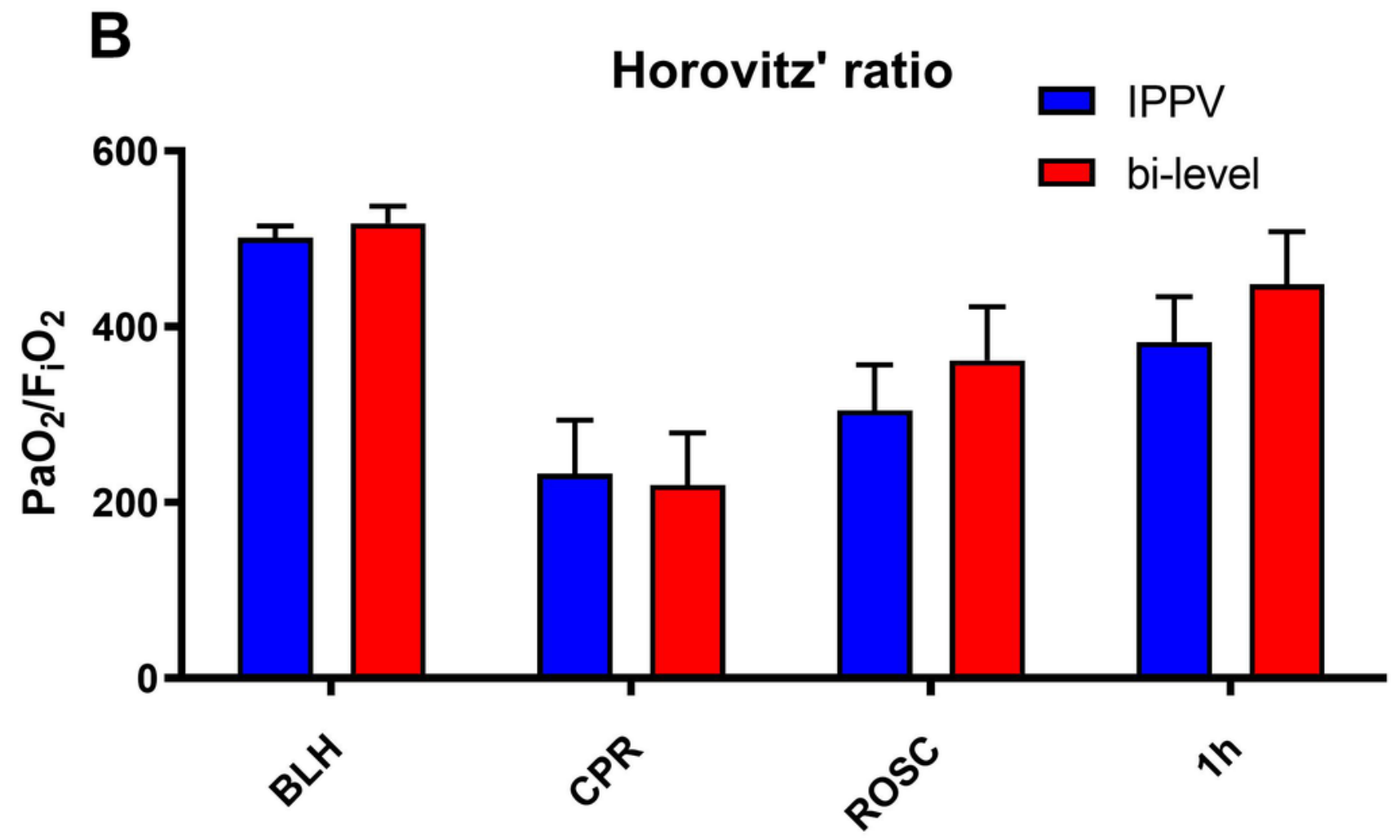




\section{Figure 2}

\section{Ventilatory pressures}

Ventilation parameters. Depicted are peak inspiratory pressures $(\mathbf{A})$, mean airway pressures (B) and mean tidal volumes (C) over different time points (baseline healthy (BLH), CPR, ROSC and 1 hour after ROSC). Peak inspiratory pressures were significantly lower in bilevel animals $(P=0.005)$ during ROSC with no statistically significant difference in tidal volumes $(P=0.16)$ or mean airway pressures $(P=0.11)$. Post-ROSC, bilevel animals tended to lower inspiratory pressures without statistical significance. No changes were detected after the $1 \mathrm{~h}$ time point. 


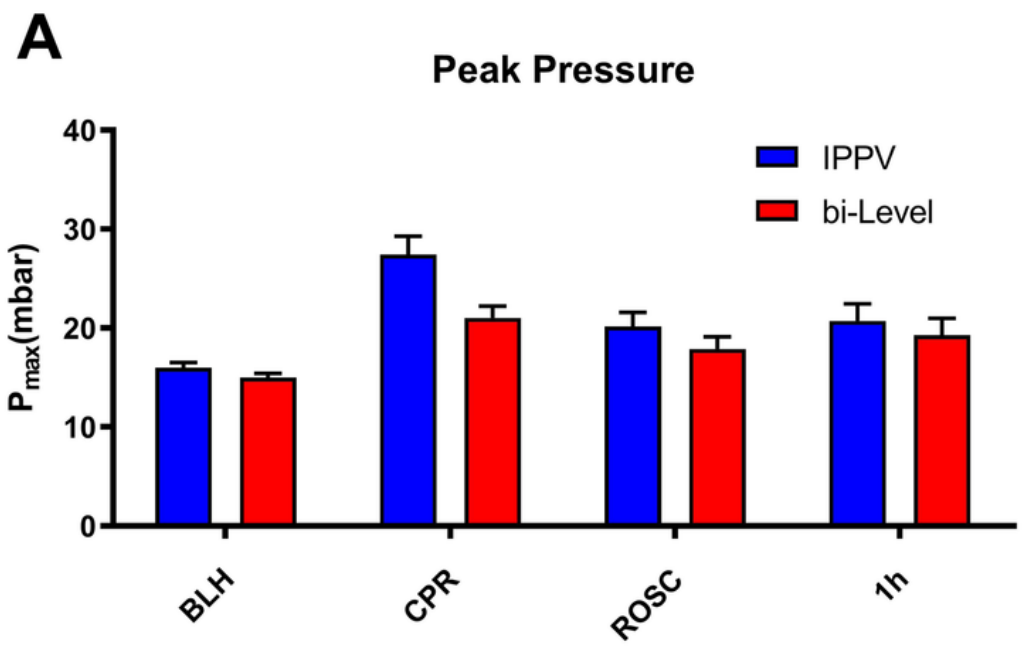

Time Point

B

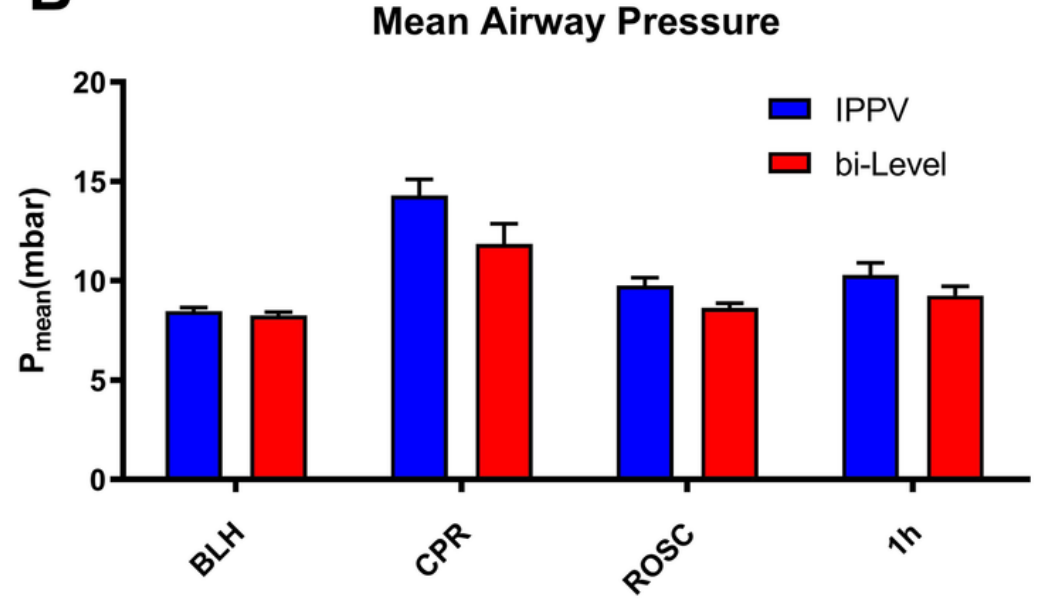

Time Point

C

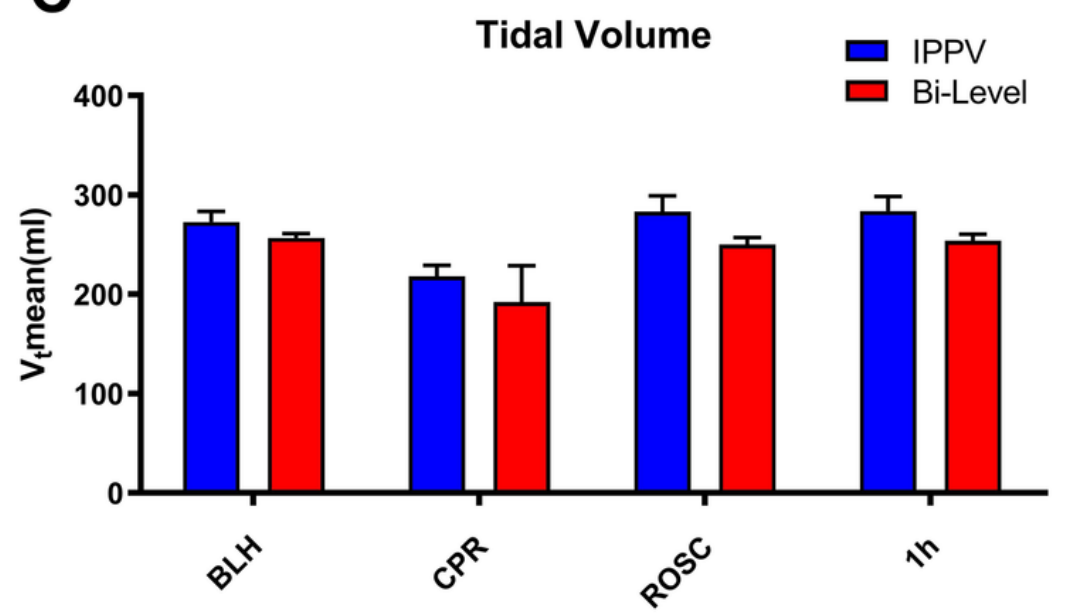

Time Point 
Figure 3

Pulmonary shunt values

MIGET measurements of pulmonary shunt-(A), low- (B), medium- (C) and high (D) ventilation/perfusion ratio volumes over different time points (baseline healthy (BLH), CPR, ROSC, 3 hours and 6 hours after ROSC). Directly after achieving ROSC, the animals showed significantly less shunt after bi-level ventilation $(P=0.017)$. There were no differences in low, middle or high ventilation/perfusion areas.
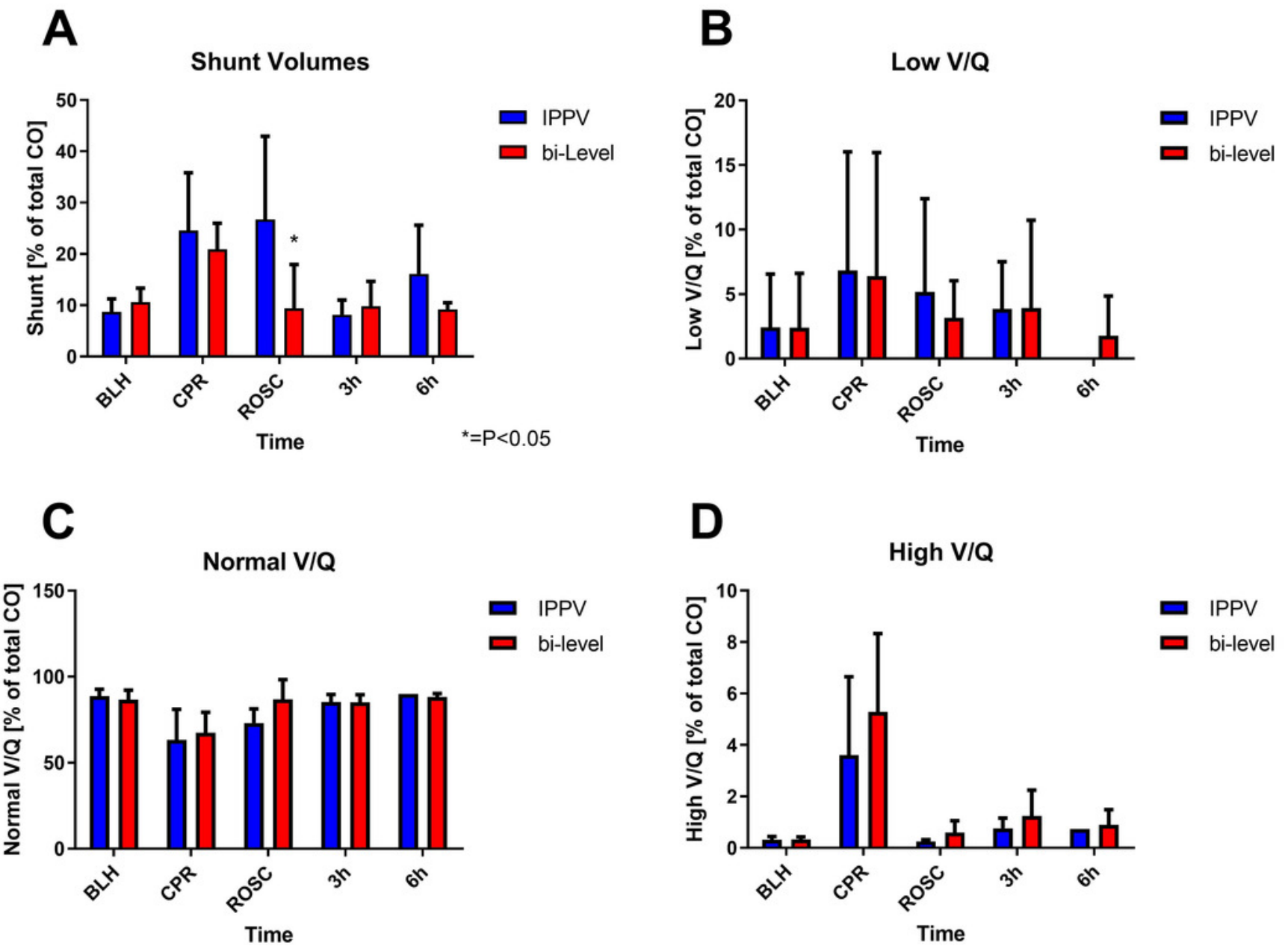


\section{Figure 4}

Tissue sample analyses

Inflammatory marker expressions of interleukin-6 (IL-6, A,B) and tumour necrosis factor alpha (TNF alpha, C,D) in cortical and hippocampal tissue relative to PPIA expression. While there were no statistical differences in cortical samples, hippocampal tissue showed decreased expression levels of TNFalpha and IL-6. Statistical analyses only proved to be significant for TNFalpha $(P=0.032)$.

A

\section{IL-6 Cortex}

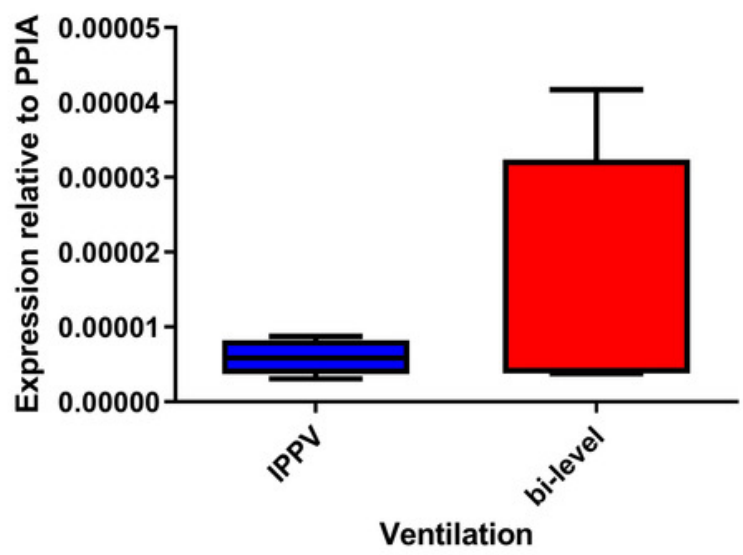

C

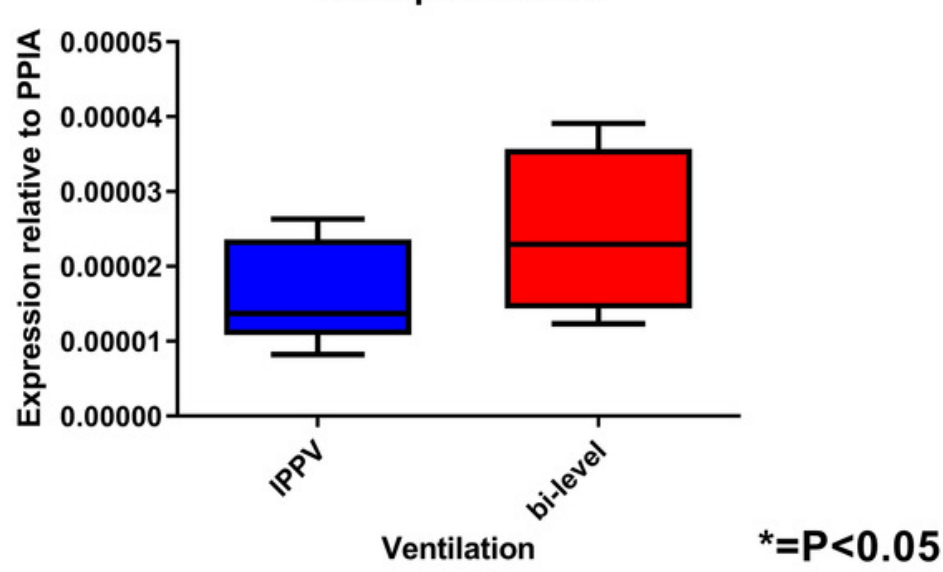

B

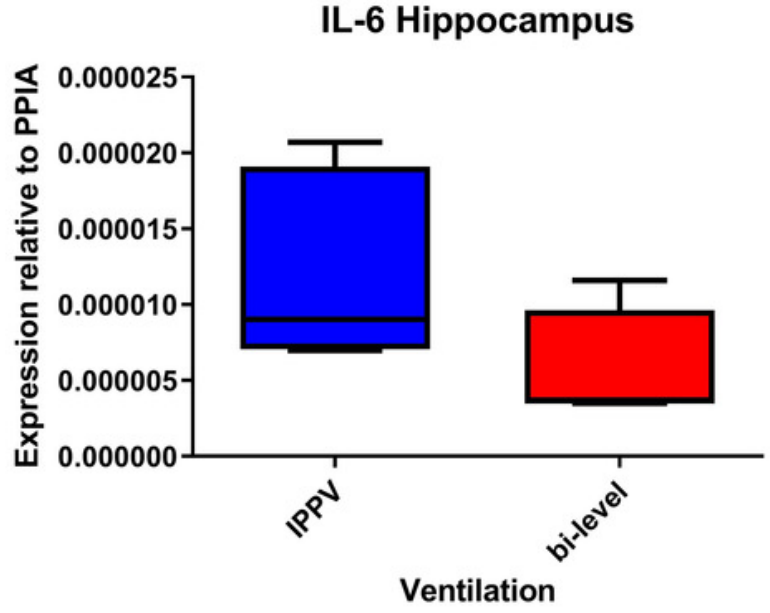

D TNFalpha Hippocampus

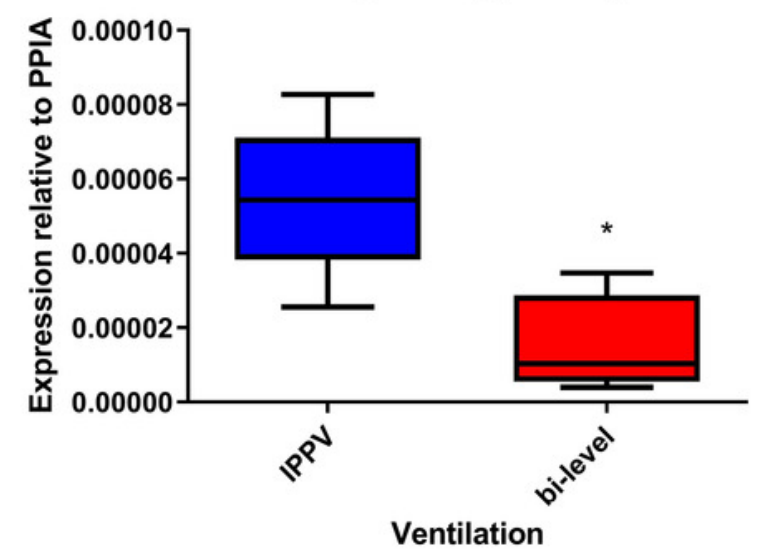




\section{Table 1 (on next page)}

Overview of vital parameters

$\mathrm{BLH}=$ base line healthy, $\mathrm{CPR}=$ measurement after 4 minutes $\mathrm{CPR}, \mathrm{ROSC}=$ measurement 10 minutes post ROSC 


\begin{tabular}{|c|c|c|c|c|c|c|}
\hline $\begin{array}{l}\text { Parameter } \\
\text { MEAN (SD) }\end{array}$ & & BLH & CPR & ROSC & $1 \mathrm{~h}$ & $5 h$ \\
\hline$H R$ & IPPV & $77(19)$ & 101(0) & $149(38)$ & $110(22)$ & $89(19)$ \\
\hline$[\mathrm{bpm}]$ & bi-Level & $70(15)$ & $101(0)$ & $141(57)$ & $117(13)$ & $123(32)$ \\
\hline MAP & IPPV & $75(7)$ & $34(17)$ & $105(13)$ & $72(10)$ & $72(9)$ \\
\hline [mmHg] & bi-Level & $73(10)$ & $30(11)$ & $84(27)$ & $68(4)$ & $65(8)$ \\
\hline CVP & IPPV & $10(2)$ & $29(12)$ & $12(1)$ & $11(3)$ & $9(4)$ \\
\hline$[\mathrm{mmHg}]$ & bi-Level & $9(6)$ & $21(9)$ & $8(3)$ & $9(3)$ & $6(3)$ \\
\hline PAP & IPPV & $22(4)$ & $52(25)$ & $22(9)$ & $25(2)$ & $19(3)$ \\
\hline [mmHg] & bi-Level & $22(6)$ & $56(22)$ & $22(2)$ & $25(2)$ & $18(4)$ \\
\hline $\mathrm{Cl}$ & IPPV & $4.03(0.5)$ & \# & $4.26(1.4)$ & $3.57(0.5)$ & $3.51(0.7)$ \\
\hline$\left[(1 / \mathrm{min}) / \mathrm{m}^{2}\right]$ & bi-Level & $3.92(0.9)$ & \# & $3.03(1.2)$ & $2.97(0.5)$ & $3.13(0.6)$ \\
\hline $\mathrm{NE}$ & IPPV & 0 & 0 & $1.1(0.97)$ & $1(0.71)$ & $0.28(0.4)$ \\
\hline$[\mathrm{mg} / \mathrm{h}]$ & bi-Level & 0 & 0 & $0.6(0.43)$ & $1.25(0.92)$ & $0.13(0.15)$ \\
\hline $\mathrm{T}$ & IPPV & $36.6(1)$ & $36.6(1)$ & $36.9(1.2)$ & $37.7(1.3)$ & $38.5(0.8)$ \\
\hline$\left[{ }^{\circ} \mathrm{C}\right]$ & bi-Level & $36.4(0.8)$ & $36.5(1)$ & $36.8(0.3)$ & $37.1(0.7)$ & $38.4(0.9)$ \\
\hline FRC & IPPV & $657(152)$ & \# & $478(135)$ & 529(119) & $453(176)$ \\
\hline$[\mathrm{ml}]$ & bi-Level & $676(102)$ & $\#$ & $480(123)$ & $517(210)$ & $471(146)$ \\
\hline Lactate & IPPV & $2.1(1.1)$ & $6.1(2.3)$ & $9.3(2.5)$ & $6.8(1.8)$ & $1.9(0.7)$ \\
\hline [mmol/l] & bi-Level & $1.9(1.4)$ & $5.8(2.3)$ & $7.3(3.4)$ & $8.2(0.9)$ & $2.5(0.7)$ \\
\hline $\mathrm{SvO}_{2}$ & IPPV & 69(19) & $28(8)$ & $51(19)$ & $48(6)$ & $51(5)$ \\
\hline [\%] & bi-Level & $67(9)$ & $25(5)$ & $51(13)$ & $51(3)$ & $52(14)$ \\
\hline \multicolumn{7}{|c|}{$\begin{array}{l}\text { Table 1: } \quad \mathrm{HR}=\text { heart rate; } \mathrm{MAP}=\text { mean arterial pressure; } \\
\mathrm{CVP}=\text { central venous pressure; } \mathrm{Cl}=\text { cardiac index } \\
\mathrm{PAP}=\text { pulmonary arterial pressure; } \mathrm{NE}=\text { norepinephrine; } \\
\mathrm{T}=\text { temperature; } \mathrm{FRC}=\text { functional residual capacity; } \\
\quad \mathrm{SVO}_{2}=\text { central venous oxygen saturation }\end{array}$} \\
\hline
\end{tabular}


1

Peer] reviewing PDF | (2019:12:43729:2:0:NEW 29 Mar 2020) 